${ }^{2}$ School of Biological Sciences, Stopford Building, Oxford Road, University of Manchester, Manchester MI3 9PT, UK)

The fermentation of cellulosic substrates by gut anaerobic fungi is usually determined in batch culture by gravimetric measurements of dry matter loss or by quantification of fermentation endproducts [1]. These techniques involve destructive sampling of the cultures, thereby requiring many replicate cultures in timecourse studies. Recently, a simple gas production technique employing a pressure transducer has been developed [2]. This new technique can be used to follow the growth of gut anaerobic fungi on particulate substrates without destructive sampling and thus it is possible to obtain an entire growth curve from a single culture bottle.

In the present study, 30 gut fungal isolates, belonging to the genera Neocallimastix and Piromyces, were used to ferment wheat straw (10g dry matter (DM) $1^{-1}$ ). DM losses were determined after harvest at the end of a $160 \mathrm{~h}$ fermentation period, with the values ranging from 38$60 \%$. Gas production was measured at 4$24 \mathrm{~h}$ intervals, with total cumulative values ranging from $100-150 \mathrm{ml}$ gas. The ranking order for total cumulative gas production was similar to that for DM loss, suggesting that the gas production profiles were reliable indicators of fungal growth. $\mathrm{Cu}-$ mulative gas production profiles were fitted to the model described by France et al. [3], and predicted values for the growth parameters, asymptotic gas pool size, and specific growth rate at the time of half final gas pool were obtained. Lag-times ranged from 16-26h and all isolates, except one, showed similar specific growth rates, with values ranging from 0.031 -
$0.042 \mathrm{~h}^{-1}$. The difference between the measured and asymptotic final gas pool size was found to be less than $3 \%$ for all isolates. From the experiment, 16 isolates were identified as good digesters of large amounts of plant material and these isolates also produced high levels of gas. The growth parameter values and DM loss data were also subjected to a Canonical Variate Analysis [4] and a hierarchical cluster tree was constructed. The results showed that of 30 isolates 20 can be formed into two main groups at the $90 \%$ similarity level and the other 10 isolates grouped at lower levels of similarity. Generally, these groupings were similar to those observed from DM loss and gas production data.

1. Lowe SE, Theodorou MK, Trinci APJ (1987) Appl Environ Microbiol 53, 12101215

2. Theodorou MK, Davies DR, Nielsen BB, Lawrence MIG, Trinci APJ (1995) Microbiol 141, 671-678

3. France J, Dhanoa MS, Theodorou MK, Lister SJ, Davies DR, Isaac D (1993) J Theoret Biol 163, 99-111

4. Genstat 5 Reference Manual (1987) Clarendon Press, Oxford, UK

\section{RUMEN PROTOZOA}

Effect of sampling site on concentration and fibrolytic activity of protozoa in bovine rumen contents. $C$ Martin, E Devillard, M Fabre, L Genestoux, B Michalet-Doreau (INRA, Station de Recherches sur la Nutrition des Herbivores, Centre de Clermont-Theix, 63122 Saint Genès-Champanelle, France)

An apparent heterogeneity or stratification within the ingested food materials and 
Ciliate numbers $\left(\times 10^{3} \mathrm{ml}^{-1}\right), \mathrm{pH}$ and activities of protozoal enzymes (nmol mg ${ }^{-1}$ protein $\mathrm{h}^{-1}$ )

\begin{tabular}{|c|c|c|c|c|c|c|c|}
\hline & \multicolumn{3}{|c|}{ Hay } & \multicolumn{4}{|c|}{ Hay + barlev } \\
\hline & $D S$ & $V S$ & $A S$ & $D S$ & $V S$ & $A S$ & $S$ \\
\hline $\mathrm{pH}$ & 6.68 & 6.83 & 6.87 & 6.27 & 6.47 & 6.60 & 0.16 \\
\hline Entodiniomorphs & 69 & 56 & 47 & 1192 & 912 & 874 & 227 \\
\hline Xylanase & 3413 & 2511 & 2091 & 2605 & 2746 & 2319 & 1173 \\
\hline Avicelase & 903 & 713 & 707 & 1204 & 1009 & 1021 & 323 \\
\hline$\beta$-D-Xylosidase & 230 & 187 & 169 & 259 & 235 & 212 & 91 \\
\hline$\beta$-D-Glucosidase & 2869 & 1866 & 2234 & 2035 & 1865 & 1879 & 815 \\
\hline
\end{tabular}

microbial populations which form the content of the reticulo-rumen generally is observed. The bacterial concentration is higher in rumen samples taken from the dorsal sac than from the ventral sac. However, information is not available on the location of protozoa and, more particularly, on the distribution of their enzyme activities in the rumen. The objective of this experiment was therefore to determine effects of sampling site within the rumen on the concentration and fibrolytic activity of protozoa.

Four ruminally cannulated cows fed twice daily were used to compare rumen contents obtained from three sampling sites in the rumen when animals were fed two different diets $\left(7 \mathrm{~kg} \mathrm{DM} \mathrm{d}^{-1}\right)$ of $100 \%$ hay or, $40 \%$ hay plus $60 \%$ barley. Samples were collected from the dorsal (DS), ventral (VS) and anterior (AS) sacs $1 \mathrm{~h}$ prior to and $3 \mathrm{~h}$ after morning feeding on two sampling days with a two-day interval. Rumen contents were strained to obtain a liquid phase from which $\mathrm{pH}$ measurements, protozoal counts and extraction of protozoal enzymes by sonication under anaerobic conditions were made. Polysaccharidase and glycosidase activities were measured respectively by the amount of reducing sugar released from xylan or Avicel (cellulose) or $p$-nitrophenol from the nitrophenol derivatives of xylose and glucose. Results reported here are means of the two sampling times.

The distribution of protozoa in term of concentration and fibrolytic activity was different in the three sampling sites of the reticulo-rumen (Table). Irrespective of diet and sampling time, the major proportion of entodiniomorphs, representing the major population of protozoa, was found in the dorsal sac $(40 \%$ mean; $\mathrm{P}<0.01)$ compared to the bottom of the reticulorumen. The specific activity of all studied fibrolytic enzymes was correspondingly significantly greater $(P<0.05)$ in the top of rumen than in the ventral or anterior sacs. The low $\mathrm{pH}$ values $(\mathrm{P}<0.001)$ observed in the dorsal sac indicated a higher fermentative activity in this site than in the other parts of the rumen. Consequently, the protozoa may contribute more than was previously thought to the great digestive potential present at the top of the rumen classically attributed to bacteria.

Effect of rumen protozoa on the degradation of neutral sugars from plant cell walls. JP Jouany, A Cornu, F Mathieu, J Senaud (INRA, Station de Recherches sur la Nutrition des Herbivores, Centre de Clermont-Theix, 63122 Saint Genès-Champanelle, France) 